
\title{
during COVID-19 pandemic
}

\author{
Fauzia A. Khan, MBBS, FCPS, FRCA \\ Professor, Department of Anesthesiology, Aga Khan University, Karachi, Pakistan. \\ Correspondence: Professor Fauzia A. Khan, Department of Anesthesiology, Faculty of Health Sciences, Medical College, Aga \\ Khan University, Stadium Road, P.O. Box 3500, Karachi 74800, Pakistan. E-mail: fauzia.khan@aku.edu
}

\section{Abstract}

Anesthesiologists have been at the forefront of COVID-19 pandemic and are particularly at risk of suffering both physical and emotional effects. There have been several individual and organizational strategies that can be put in place to tackle their well-being. Self-strategies that are recommended are adequate rest and sleep, consistent work breaks, help seeking behavior, emotional control and acceptance of limitations of their own competence and healthcare systems. Several online training programs are available for individual guidance. Organizations can also support their staff in different ways. It is important to recognize those who are more vulnerable physically and emotionally. Institution should implement stress reduction strategies, provide adequate PPE, should be able to communicate with their employees in a clear and honest manner and enforce infection control policies. In addition, institutions must take other physical measures where resources permit, like provision of negative pressure rooms and to provide updated and accurate information. Both personal and psychological support is needed. Several different models have been suggested for emotional support. One particularly vulnerable group that requires additional assistance are those in quarantine. Last but not least, in addition to the implementation of all these measures it is imperative to sustain these activities.

Key words: Anesthesiology; Anesthesiologists; COVID-19; Stress, Psychological

Citation: Khan FA. Anesthesiologists' occupational wellbeing and support during COVID-19 pandemic. Anaesth. pain intensive care 2021;25(2):122-125. DOI: 10.35975/apic.v25i2.1459

Received: 21 February 2021, Accepted: 25 February 2021

\section{Introduction}

There have been several potential stressors in the working life of an anesthesiologist. These are sustained vigilance, rapid decision making, swift and safe actions, dealing with critical situations, expanded scope of work, and production demands. Anesthesiologists are in the forefront of COVID-19 response and it has added several new stress factors like overwork, susceptibility to infections, dealing with lack of personal protective equipment (PPE) etc. ${ }^{1}$ There is now plenty of evidence that stress can affect the emotional state of the care giver. Several reports from different countries during the first wave of COVID-19 pointed out that physicians and nurses involved in care are affected by fear, anxiety, depression, moral injury, post-traumatic distress and burnout. ${ }^{2-5}$ There is an urgent need to offer individual and organizational support to those on the forefront of this pandemic.

\section{Self-Management Strategies}

First, it is important to realize that we are all human and acknowledging what is in our control and what is not. Self-strategies that are recommended are, taking regular and consistent work breaks, adequate sleep, and maintaining a healthy lifestyle with regular 
exercise. ${ }^{6}$ One should try developing a help seeking behavior and be aware how to access external/peer support. Also, one should also accept the limitations of what your health system can offer and do for you.

Several online training programs are available. One example of such program is through digital learning package, where evidence-based guidelines are available on communication, social stigma, self-care strategies, and managing emotions. ${ }^{7}$

Joining a support group also helps by allowing one to vent out inner feelings, consensual validation, peer support and peer learning. ${ }^{8}$ Most programs are conducted by telehealth and individual or group counseling can be made available.

\section{Offering Support to Colleagues}

Colleagues and friends can be an important source of support for each other and part of maintaining wellbeing. One can help by exploring causes of distress, offer the opportunity to talk, be kind and reassuring, and guide colleagues to available resources. ${ }^{9,10}$

\section{Institutional Responsibilities}

Institutions can support their staff in several different ways, by identifying more vulnerable, implementation of stress reduction strategies, access to PPE, educating and training them in communication and infection control, providing resources and offering personal and psychological support.

Some of the risk factors have been recognized in individuals, who need more support are, younger and more junior colleagues, females, especially older and those not in relationships, parents of dependent children, those with infected family members, and those in quarantine. ${ }^{11}$ This recognition is even more important where there are resource limitations so that help can be preferentially offered to the vulnerable group.

Institutions should also implement general stress reduction strategies i.e. maintaining safe working hours and rest days, focus on dynamic work roles, rotating allocation of complex cases, being accessible, ensuring personal safety and undertaking regular briefings. There should be clear role expectations. ${ }^{12}$

One of the major risk factors with both physical and mental health impact is inadequate, or improper PPE use. In a survey conducted by RCOA over two third of the anesthetists were concerned about lack of PPE. ${ }^{13}$
There have been news reports of doctors dying by suicide because of fear of infecting themselves and their near and dear ones. ${ }^{14}$

The importance of communication in the organization cannot be emphasized enough. The key principle is to be open and honest and hold a two-way dialog with the employees. Both short-term and long-term interventions are needed. ${ }^{15}$ There should be clear direction and enforcement of infection control procedures. Kiseley et al. ${ }^{11}$ looked at past outbreaks of SARS, MERS, EBOLA, and presently COVID and recommended following; sufficient supply of PPE, redesigning of procedures posing high risk of spread of infections and improving safety. Several websites, articles and videos support the well-being of healthcare providers. ${ }^{16,17}$ Each organization should have a mechanism for guiding their staff to the best of their ability. Good and caring organizations should also provide personal support by arranging alternate accommodation of staff who are worried about infecting their families and guarantying food and living supplies for those who are quarantined and have no family support. Last but not the least is the area of psychological support by recognizing staff efforts and access to psychological interventions when required.

Several models have been suggested for emotional support. ${ }^{18}$ One such model is the pyramidal model, which may be helpful in resource-constrained countries. $^{19}$ In this model initially, broad-based practical information is offered to all members, then those from high-risk departments are screened and provided emotional support. Finally, mental help services are offered to individuals who are high-risk. The stress inoculation method for promoting resilience has also been suggested. ${ }^{20}$

A vulnerable group, who requires additional assistance are those in quarantine. Some measures that can be taken to decrease stress in this particular group are to keep them updated, encourage them to communicate with their teams, offer online support from psychologists and encourage exercise and meditation. $^{21}$

Peer support projects based on social media with application on smartphone have also been published and can be replicated. ${ }^{10}$

Leadership during crisis is always challenging. Leaders should themselves model good practice and 
behavior, build and listen to their teams, allocate resources and anticipate future challenges. Different leadership models have been proposed. ${ }^{22}$

Anesthetic literature on the topic is scanty. ${ }^{23,24}$ With anesthesiologists in the forefront of this pandemic, we must examine the emotional impact of this disease on this particular group, document it and device-specific strategies.

\section{Conclusion}

In conclusion, both individual and organizational factors can help protect both physical and emotional well-being of anesthesiologists, who are at the forefront in the fight against this pandemic. A lot of data is being generated globally but interventions at the national level are needed. It is also important not just to implement but also to sustain these actions.

\section{Conflict of interest}

None declared by the author.

\section{Author's contribution}

The author conceived the idea and is the sole author of this manuscript.

\section{References}

1. Saadat $\mathrm{H}$, Kain $\mathrm{Z} \mathrm{N}$.Wellness interventions for anesthesiologists. Curr Opin Anesthesiol. 2018;31:375381. [PubMed] DOI: $10.1097 / A C 0.0000000000000598$

2. Luo M, Guo L, Yu M, Jiang W, Wang $H$. The psychological and mental impact of coronavirus disease 2019 (COVID-19) on medical staff and general public A systematic review and meta-analysis. Psychiatry Res. 2020 Sep;291:113190. [PubMed] DOI: 10.1016/.jpsychres.2020.113190

3. Walton M, Murray E, Christian MD. Mental health care for medical staff and affiliated healthcare workers during the COVID-19 pandemic. Eur Heart J Acute Cardiovasc Care. 2020 Apr;9(3):241-247. [PubMed] DOI: $\underline{10.1177 / 2048872620922795}$

4. Pappa S, Ntella V, Giannakas T, Giannakoulis VG, Papoutsi E, Katsaounou P. Prevalence of depression, anxiety, and insomnia among healthcare workers during the COVID-19 pandemic: A systematic review and meta-analysis. Brain Behav Immun. 2020 Aug;88:901907. [PubMed] DOI: $10.1016 /$ j.bbi.2020.05.026

5. Preti E, Di Mattei V, Perego G, Ferrari F, Mazzetti M, Taranto $P$, et al. The psychological impact of epidemic and pandemic outbreaks on healthcare workers: rapid review of the evidence. Curr Psychiatry Rep. 2020 Jul
10;22(8):43. [PubMed] DOI: 10.1007/s11920-020$\underline{01166-z}$

6. Unadkat S, Farquhar M. Doctors' wellbeing: self-care during the covid-19 pandemic. BMJ. 2020 Mar 24;368:m1150. [PubMed] DOI: $10.1136 / \mathrm{bmi} . \mathrm{m} 1150$

7. Blake $H$, Bermingham $F$, Johnson $G$, Tabner $A$. Mitigating the psychological impact of covid-19 on healthcare workers: a digital learning package. Int J Environ Res Public Health. 2020 Apr 26;17(9):2997. [PubMed] DOI: 10.3390/ijerph17092997

8. Viswanathan R, Myers MF, Fanous AH. Support Groups and Individual Mental Health Care via Video Conferencing for Frontline Clinicians During the COVID19 Pandemic. Psychosomatics. 2020 SepOct:61(5):538-543. [PubMed] DOI: 10.1016/j.psym.2020.06.014

9. Walton M, Murray E, Christian MD. Mental health care for medical staff and affiliated healthcare workers during the COVID-19 pandemic. Eur Heart J Acute Cardiovasc Care. 2020 Apr;9(3):241-247. [PubMed] DOI: 10.1177/2048872620922795

10. Cheng $P$, Xia G, Pang $P$, Wu B, Jiang W, Li YT, et al. COVID-19 epidemic peer support and crisis intervention via social media. Community Ment Health J. 2020 Jul;56(5):786-792. [PubMed] DOI: 10.1007/s10597$\underline{\text { 020-00624-5 }}$

11. Kisely S, Warren N, McMahon L, Dalais C, Henry I, Siskind D. Occurrence, prevention, and management of the psychological effects of emerging virus outbreaks on healthcare workers: rapid review and meta-analysis. BMJ. 2020 May 5;369:m1642. [PubMed] DOI: 10.1136/bmi.m1642

12. Rangachari $P, L$ Woods J. Preserving organizational resilience, patient safety, and staff retention during covid-19 requires a holistic consideration of the psychological safety of healthcare workers. Int J Environ Res Public Health. 2020 Jun 15;17(12):4267. [PubMed] DOI: $10.3390 /$ ijerph17124267

13. Royal College of Anaesthetists (RCOA) News. Over two thirds of anaesthetists feel concerned for their health over a lack of PPE. Available from: https://www.rcoa.ac.uk/news/over-two-thirdsanaesthetists-feel-concerned-their-health-over-lackppe (Accessed on 13 th January 2021)

14. Lennon JC. What lies ahead: Elevated concerns for the ongoing suicide pandemic. Psychol Trauma. 2020 Aug;12(S1):S118-S119. [PubMed] DOI: $10.1037 /$ tra0000741

15. Nelson SM, Lee-Winn AE. The mental turmoil of hospital nurses in the COVID-19 pandemic. Psychol Trauma. 2020 Aug;12(S1):S126-S127. [PubMed] DOI: $10.1037 /$ tra0000810

16. World Federation of the Societies of Anaesthesiologists (WFSA). COVID-19 guidance for anaesthesia and perioperative care providers. Available from: https://wfsahq.org/resources/covid-19/ (Accessed on $11^{\text {th }}$ January 2021) 
17. APA COVID-19 Information and Resources: Available from: https://www.apa.org/topics/covid-19 (Accessed on $12^{\text {th }}$ February 2021)

18. Haller M, Norman SB, Davis BC, Capone C, Browne K, Allard CB. A model for treating COVID-19-related guilt, shame, and moral injury. Psychol Trauma. 2020 Aug;12(S1):S174-S176. [PubMed] DOI: $\underline{10.1037 / \text { tra0000742 }}$

19. Miotto K, Sanford J, Brymer MJ, Bursch B, Pynoos RS. Implementing an emotional support and mental health response plan for healthcare workers during the COVID19 pandemic. Psychol Trauma. 2020 Aug;12(S1):S165S167. [PubMed] DOI: $10.1037 /$ tra0000918

20. Albott CS, Wozniak JR, McGlinch BP, Wall MH, Gold BS, Vinogradov S. Battle buddies: rapid deployment of a psychological resilience intervention for health care workers during the covid-19 pandemic. Anesth Analg. 2020 Jul;131(1):43-54. [PubMed] DOI: 10.1213/ANE.0000000000004912
Brooks SK, Webster RK, Smith LE, Woodland L, Wessely S, Greenberg N, et al. The psychological impact of quarantine and how to reduce it: rapid review of the evidence. Lancet. 2020 Mar 14;395(10227):912920. [PubMed] DOI: $10.1016 / \mathrm{S} 0140-6736(20) 30460-8$

21. Nicola M, Sohrabi C, Mathew G, Kerwan A, Al-Jabir A, Griffin M, Agha M, Agha R. Health policy and leadership models during the COVID-19 pandemic: A review. Int J Surg. 2020 Sep;81:122-129. [PubMed] DOI: 10.1016/j.jijsu.2020.07.026

22. McCartney CJ, Mariano ER. COVID-19: bringing out the best in anesthesiologists and looking toward the future. Reg Anesth Pain Med. 2020 Aug;45(8):586-588. [PubMed] DOI: 10.1136/rapm-2020-101629

23. Fleisher LA, Sweeny RE, Clapp JT, Barsade SG. Managing anxiety in anesthesiology and Intensive care providers during the COVID-19 pandemic: An analysis of the psychological response of a front-line department. NEJM Catalyst. Available from: https://catalyst.nejm.org/doi/full/10.1056/CAT.20.0270 (Accessed 14th February 2021) 